\title{
Diagnosis and Management of Gestational Diabetes with Oral Glucose Tolerance Test and HBA1C
}

\section{Anjana Chaudhary ${ }^{1}$, Baljeet Kaur Bhatia ${ }^{2}$}

Section: Healthcare

Sci. Journal Impact

Factor: 6.1 (2018)

ICV: 90.90 (2018)

(c) (i) (5)

Copyright@IJCRR
'Associate Professor Department of Obstetrics and Gynecology Chandulal Chandrakar Memorial Medical College, Kachandur, Durg, Chattisgarh-490024, India; ${ }^{2}$ Assistant Professor Department of Obstetrics and Gynecology Shri Shankaracharya lnstitute of Medical Sciences Junwani, Bhiali, Chattisgarh-490020, India.

\section{ABSTRACT}

Introduction: Gestational diabetes mellitus (GDM) is a potentially serious and prevalent condition such as fetal growth abnormalities, shoulder dystocia, birth injury, prematurity and increased Caesarean section rate, which may lead to serious effects in mothers and neonates. Recently $\mathrm{HbA} 1 \mathrm{c}$ used diagnostic criterion for diabetes (DM).

Objective: Diagnosis and Management of Gestational Diabetes with Oral Glucose Tolerance Test and Hba1c.

Methods: A total of 241 pregnant women recruited in the study. Pregnant women in prenatal care, without previous DM, were included to perform OGTT tests in the third trimester of pregnancy. written informed consent was obtained from all the patients.

Results: All the patients were between 23 and 35 years of age in the third trimester of pregnancy (gestational age $=27 \pm 5$ weeks). In patients without GDM mean SBP was $110 \pm 11.8$ and with GDM 119 \pm 12.6 ( $p<0.001)$. In cases without GDM mean DBP ( Diastolic blood pressure) was $70 \pm 8.4 \mathrm{mmHg}$ and with GDM $82 \pm 15.1 \mathrm{mmHg}(p<0.001)$. In patients without GDM mean FBS (Fasting blood sugar) was $77.4 \pm 9.4$ and with GDM $95.4 \pm 12.6 \mathrm{mg} / \mathrm{dl}$. Mean $1 \mathrm{hrs}$. Glucose was $120.6 \pm 12.4$ in patients without GDM and with GDM it was 176.8 \pm 16.4 . In patients without GDM mean 2 HRS. Glucose was $115.2 \pm 11.4$ and with GDM 147 \pm 15.4 . In patients without GDM mean $\mathrm{HbA} 1 \mathrm{c}$ was $5.2 \pm 0.3$ and with GDM 5.9 \pm 0.6 ( $p<0.001$ ). In patients without GDM mean $\mathrm{Hb}$ was $11.6 \pm 0.7$ and with GDM $11.8 \pm 0.5$ ( $p$ 0.022). In patients without GDM mean Cholesterol was $210 \pm 22.4$ and with GDM $225 \pm 35.7$ $(p<0.001)$.

Conclusion: Different HbA1c cut-off points may be useful in a diagnostic tool for GDM in combination with OGTT. This will result in a considerable decrease in the research workload on both patients and the testing centre, employees and equipment.

Key Words: Gestational diabetes mellitus, GDM, HbA1c, Hb, Cholesterol, Blood glucose

\section{INTRODUCTION}

Gestational diabetes mellitus (GDM) is a potentially serious and prevalent condition such as fetal growth abnormalities, shoulder dystocia, birth injury, prematurity and increased Caesarean section rate, which may lead to serious effects in mothers and neonates. ${ }^{1,2}$ The risk of adverse perinatal and maternal outcomes are directly proportional to the level of hyperglycaemia, and there is a linear relationship between maternal glucose and various neonatal outcomes. ${ }^{3}$ Detection of GDM and treatment reduces the risks for the mothers as well as for the neonates. ${ }^{3}$

Customarily, the OGTT has been the test of choice for this condition. It can be preceded by a screening methodology, for example, fasting glycemia (FG) or a glucose load test.
But still are controversies regarding OGTT cut-offs which should be used for the diagnosis of GDM and also a recent review concluded that the evidence is insufficient to permit assessment of which strategy is best to diagnose GDM. ${ }^{4}$ $\mathrm{HbA} 1 \mathrm{c}$ test as a diagnostic criterion for diabetes (DM) in the general population and was included in 2010 by the American Diabetes Association (ADA). The cut-off of $\mathrm{HbAlc} \geq 48$ $\mathrm{mmol} / \mathrm{mol}(6.5 \%)$ was set up for the conclusion, and was endorsed by the World Health Organization (WHO) in 2011., However weak agreement was seen in between $\mathrm{HbAlc}$ and glucose tests and these two tests may identify different populations of patients. ${ }^{7}$

OGTT is a cumbersome test which is time-consuming, labour intensive and generally poorly tolerated by pregnant women. It is important to fasten the patient, sit for more

\section{Corresponding Author:}

Dr. Anjana Chaudhary, Associate Professor, Dept. of Obstetrics and Gynecology, Chandulal Chandrakar Memorial Medical College, Kachandur, Durg, Chattisgarh-490024, India.

ISSN: 2231-2196 (Print) ISSN: 0975-5241 (Online)

Received: $10.09 .2020 \quad$ Revised: 12.10 .2020

Accepted: 15.11 .2020

Published: 05.01 .2021 
than $2 \mathrm{~h}$ and have at least three venipunctures. Pregnant women are susceptible to nausea and vomiting from delayed emptying of the stomach. This may contribute to an invalid test result, combined with gestational oedema compromising venous access. Also, the recommendation for universal screening has greatly increased the research burden. HbAlc is the result of glucose's irreversible nonenzymatic binding to plasma proteins, in particular haemoglobin. (Hb).HbA1c is a single, non-fasting blood test and reflects glucose levels over the previous 4 to 8 weeks. $\mathrm{HbA} 1 \mathrm{c}$ has been shown to have greater reliability compared to glucose monitoring. ${ }^{8,9}$

Based on this study was carried out to analyse $\mathrm{HbAlc}$ test for detection of GDM based on OGTT as a reference test.

\section{MATERIAL AND METHODS}

The present study was carried out in the department of OBGY. A total of 241 pregnant women recruited in the study. Pregnant women in prenatal care, without previous DM, were included to perform OGTT tests in the third trimester of pregnancy. written informed consent was obtained from all the patients. There have been records of the era, gestational age, obstetric background, smoking, family history of cardiovascular disease (CVD), DM, arterial hypertension (HT), alcohol intake, and drug usage. The weight and height of patients have also been reported and used to measure BMI $\left(\mathrm{kg} / \mathrm{m}^{2}\right)$ values.

Patients were excluded from the study if observed with the following conditions which are known to interfere with or lead to the misinterpretation of HbAlc results, anaemia, chronic renal disease and/or presence of haemoglobin variants. After an overnight fast, blood samples were taken to determine $\mathrm{HbA} 1 \mathrm{c}$ levels, blood cell counts, lipid profile, creatinine and glucose concentrations. The OGTT was performed according to recommendations.

All data were entered in the Excel sheet, Data were expressed as mean and SD for normally distributed variables, and as median (range) for non-Gaussian variables. Student's $T$-tests and kappa coefficients were used as appropriate.

\section{RESULTS}

A total of 241 pregnant women recruited in the study. Pregnant women in prenatal care, without previous DM, were included to perform OGTT tests in the third trimester of pregnancy and were assessed as to the presence or absence of GDM. All the patients were between 23 and 35 years of age in the third trimester of pregnancy (gestational age $=27 \pm 5$ weeks) (Table 1).

\section{Table 1: Clinical and laboratory characteristics of study participants}

Gestational diabetes mellitus (GDM)

\begin{tabular}{|c|c|c|c|}
\hline Parameters & $\begin{array}{c}\text { Without } \\
\text { GDM } \\
(\mathrm{n}=159)\end{array}$ & $\begin{array}{l}\text { With GDM } \\
\qquad(\mathbf{n}=\mathbf{8 2})\end{array}$ & P value \\
\hline Age in years & $27 \pm 5.2$ & $33 \pm 5.4$ & $<0.001$ \\
\hline Gestational age & $27 \pm 5.4$ & $26 \pm 4.5$ & NS \\
\hline $\mathrm{BMI}(\mathrm{kg} / \mathrm{mz})$ & $28 \pm 5.2$ & $31 \pm 6.8$ & $<0.001$ \\
\hline SBP (mmHg) & $110 \pm 11.8$ & $119 \pm 12.6$ & $<0.001$ \\
\hline $\mathrm{DBP}(\mathrm{mmHg})$ & $70 \pm 8.4$ & $82 \pm 15.1$ & $<0.001$ \\
\hline $\begin{array}{l}\text { Fasting glucose } \\
(\mathrm{mg} / \mathrm{dl})\end{array}$ & $77.4 \pm 9.4$ & $95.4 \pm 12.6$ & \\
\hline $\begin{array}{l}\text { 1hours glucose } \\
(\mathrm{mg} / \mathrm{dl})\end{array}$ & $120.6 \pm 12.4$ & $176.8 \pm 16.4$ & \\
\hline $\begin{array}{l}2 \text { hours } \\
\text { glucose }(\mathrm{mg} / \mathrm{dl})\end{array}$ & $115.2 \pm 11.4$ & $147 \pm 15 \cdot 4$ & \\
\hline HbAic (\%) & $5.2 \pm 0.3$ & $5 \cdot 9 \pm 0.6$ & $<0.001$ \\
\hline $\mathrm{Hb} \% \mathrm{~g} / \mathrm{dl}$ & $11.6 \pm 0.7$ & $11.8 \pm 0.5$ & 0.022 \\
\hline $\begin{array}{l}\text { Cholesterol mg/ } \\
\text { dl }\end{array}$ & $210 \pm 22.4$ & $225 \pm 35 \cdot 7$ & $<0.001$ \\
\hline
\end{tabular}

NS: Not Significant

In patients without GDM mean age was $27 \pm 5.2$ and with GDM $33 \pm 5.4(\mathrm{p}<0.001)$. In patients without GDM mean Gestational age was $27 \pm 5.2$ and with GDM it was observed as $26 \pm 4.5$ weeks. Mean BMI was observed to be $28.5 \pm 5.2$ $\mathrm{kg} / \mathrm{m}^{2}$ in cases without GDM and $31 \pm 6.8$ in GDM $(\mathrm{p}<0.001)$

In patients without GDM mean SBP was $110 \pm 11$.8and with GDM $119 \pm 12.6(p<0.001)$. In cases without GDM mean DBP (Diastolic blood pressure) was $70 \pm 8.4 \mathrm{mmHg}$ and with GDM $82 \pm 15.1 \mathrm{mmHg}(\mathrm{p}<0.001)$. In patients without GDM mean FBS (Fasting blood sugar) was $77.4 \pm 9.4$ and with GDM $95.4 \pm 12.6 \mathrm{mg} / \mathrm{dl}$. Mean $1 \mathrm{hrs}$. Glucose was $120.6 \pm 12.4$ in patients without GDM and with GDM it was $176.8 \pm 16.4$. In patients without GDM mean 2HRS.Glucose was $115.2 \pm 11.4$ and with GDM $147 \pm 15.4$. In patients without GDM mean HbA1c was 5.2 \pm 0.3 and with GDM $5.9 \pm 0.6(\mathrm{p}<0.001)$. In patients without GDM mean $\mathrm{Hb}$ was $11.6 \pm 0.7$ and with GDM $11.8 \pm 0.5$ (p 0.022). In patients without GDM mean Cholesterol was $210 \pm 22.4$ and with GDM $225 \pm 35.7(\mathrm{p}<0.001)$.

There has been a statistically important disparity between women with and without GDM in age, BMI, blood pressure and GDM history. 82 pregnant women were classified with GDM based on these results and taking into account HbA1c $(5.8 \%)$ as a guideline in the cut-off point for GDM. The agreement between the diagnoses provided in this study according to the HbA1c cut-off and the results of the OGTT was fair. 


\section{DISCUSSION}

Laboratory testing of $\mathrm{HbAlc}$ has been highly systematic and has evolved to be an easier, more reliable and automatic test to examine the importance of HbA1c for GDM diagnosis. ${ }^{10}$ As predicted, our data revealed that in pregnant women without GDM, HbA1c values were significantly lower than those seen in pregnant women with GDM. There was some overlap between the HbA1c values showed by participants in the two groups, however. These findings were in agreement with another study by Balaji et al. ${ }^{11}$ and Rajput et al. ${ }^{12}$

Differences in HbA1c values are more likely to be caused by other physiological causes during pregnancy. ${ }^{13}$ Anaemia could not describe these variations in our research, as women with and without GDM presented with similar levels of total haemoglobin. When we used the HbA1c cut-off point of (5.8 per cent) to detect participants with and without GDM, it was found that those identified as having the disorder were more likely to be older and had prior GDM and DM family history, as well as higher BMI, blood pressure (systolic and diastolic), glycemia (fasting, $1 \mathrm{~h}$ and $2 \mathrm{hG}$ ) and cholesterol levels. Due to these parameters, there is an increase chance of adverse outcome for both mother and child ${ }^{14}$. A different GDM group from that diagnosed by glucose-based tests appears to be identified by the HbA1c test. The weak diagnostic agreement between tests corroborates this fact.

In our findings, it was found that $34.02 \%$ of GDM patients were diagnosed with the HbA1c cut-off point of around $(5.8 \%)$ and that $6 \%$ of pregnant women were classified by the OGTTT as GDM negative. A study in Australia ${ }^{15}$ found that a subgroup of pregnant women had a normal OGTT but elevated $\mathrm{HbA} 1 \mathrm{c}$, indicating that a clinically significant result is $\mathrm{HbAlc}>40 \mathrm{mmol} / \mathrm{mol}$ (5.8 per cent) during pregnancy which is similar to our findings.

\section{CONCLUSION}

To conclude different HbA1c cut-off points may be useful in a diagnostic tool for GDM in combination with OGTT. This will result in a considerable decrease in the research workload on both patients and the testing centre, employees and equipment. Further investigations are needed to incorporate $\mathrm{HbA1c}$ with optimization of the cut-off value as a single non-fasting screening method for GDM.

\section{ACKNOWLEDGMENT}

Authors acknowledge the immense help received from the scholars whose articles are cited and included in references to this manuscript. The authors are also grateful to authors / editors / publishers of all those articles, journals, and books from which the literature for this article has been reviewed and discussed.

\section{Conflict of Interest: Nil}

\section{Source of Funding: Nil}

\section{REFERENCES}

1. Casey BM, Lucas MJ, McIntire DD. Pregnancy outcomes in women with gestational diabetes compared with the general obstetric population. Obstet Gynecol 1997;90:869-73.

2. World Health Organization. Definition, diagnosis and classification of diabetes mellitus and its complications: Report of a WHO consultation. Part 1: Diagnosis and Classification of Diabetes Mellitus. WHO/NCD/NCS/99 2 ed, Geneva 1999.

3. Hartling L, Dryden DM, Guthrie A, Muise M, Vandermeer B, Donovan L. Benefits and harms of treating gestational diabetes mellitus: a systematic review and meta-analysis for the U.S. Preventive Services Task Force and the National Institutes of Health Office of Medical Applications of Research. Ann Intern Med 2013; 159(2):123-9.

4. Buckley BS, Harreiter J, Damm P, Corcoy R, Chico A, Simmons D, Vellinga A, Dunne F, DALI Core Investigator Group. Gestational diabetes mellitus in Europe: prevalence, current screening practice and barriers to screening. A review. Diabet Med 2012 Jul; 29(7):844-54.

5. Farrar D, Duley L, Medley N, Lawlor DA. Different strategies for diagnosing gestational diabetes to improve maternal and infant health. Cochrane Database Syst Rev 2015; 1:CD007122.

6. American Diabetes Association. Classification and diagnosis of diabetes. Diabetes Care. 2015;38:S8-S16.

7. Cavagnolli G, Comerlato J, Comerlato C, Renz PB, Gross JL, Camargo JL. $\mathrm{HbA}(1 \mathrm{c})$ measurement for the diagnosis of diabetes: is it enough? Diabet Med 2011; 28(1):31-5.

8. Sacks DB. A1C versus glucose testing: a comparison. Diabetes Care 2011; 34(2):518-23.

9. d'Emden M. Glycated haemoglobin for the diagnosis of diabetes. Aust Prescriber 2014;37:98-100.

10. Gillery P. A history of HbA1c through Clinical Chemistry and Laboratory Medicine. Clin Chem Lab Med 2013;51:65-74.

11. Balaji V, Madhuri BS, Ashalatha S, Sheela S, Suresh S, Seshiah V. A1C in gestational diabetes mellitus in Asian Indian women. Diabetes Care 2007; 30(7):1865-7.

12. Rajput R, Yogesh Yadav, Rajput M, Nanda S. Utility of HbA1c for diagnosis of gestational diabetes mellitus. Diabetes Res Clin Pract 2012; 98(1):104-7.

13. Hiramatsu Y, Shimizu I, Omori Y, Nakabayashi M, JGA (Japan Glycated Albumin) Study Group.Determination of reference intervals of glycated albumin and hemoglobin A1c in healthy pregnant Japanese women and analysis of their time courses and influencing factors during pregnancy. Endocr J 2012; 59(2):14551.

14. HAPO Study Cooperative Research Group., Metzger BE, Lowe LP, Dyer AR, Trimble ER, Chaovarindr U, Coustan DR, Hadden DR, McCance DR, Hod M, McIntyre HD, Oats JJ, Persson B, Rogers MS, Sacks DA. Hyperglycemia and adverse pregnancy outcomes. N Engl J Med 2008; 358(19):1991-2002.

15. Rowan JA, Budden A, Sadler LC. Women with a nondiagnostic $75 \mathrm{~g}$ glucose tolerance test but elevated $\mathrm{HbA} 1 \mathrm{c}$ in pregnancy: an additional group of women with gestational diabetes. Aust N Z J Obstet Gynaecol 2014; 54(2):177-80. 